\title{
Infarctus du myocarde avec onde de Pardee
}

\section{Myocardial infarction with tombstone wave}

\section{P. Taboulet}

Reçu le 23 avril 2012 ; accepté le 4 mai 2012

(C) SFMU et Springer-Verlag France 2012

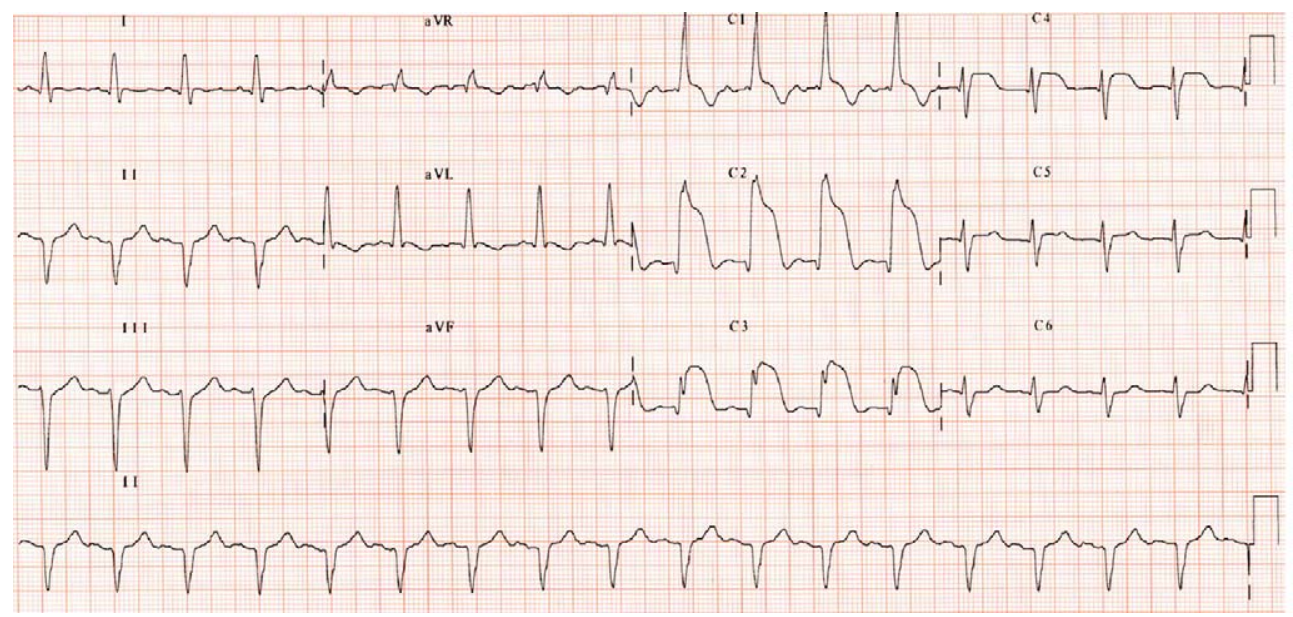

Fig. 1 A. Infarctus antérieur aigu avec onde de Pardee

Un homme de 87 ans consulte aux urgences pour une douleur médiothoracique intermittente depuis 48 heures, mais intense depuis 90 minutes. L'ECG révèle une tachycardie sinusale modérée $(102 / \mathrm{mn})$, à QRS larges $(140 \mathrm{~ms})$ avec axe hypergauche $\left(-70^{\circ}\right)$ et retard droit ( $\left(\mathrm{R}^{\prime}\right)$ compatibles avec un hémibloc antérieur gauche et un bloc de branche droit (Fig. 1). Dans les dérivations apicoseptales (V1-V4), ces QRS débutent par une onde $\mathrm{Q}$ peu profonde mais large (40 ms en V2-V3) et se poursuivent par une onde R géante (17 $\mathrm{mm}$ en V1-V2) avec distorsion terminale (onde R fragmentée avec portion descendante en partie effacée). La repolarisation est anormale de V1 à V5 où l'on note une élévation majeure du segment ST ( $\geq 10 \mathrm{~mm}$ en V2-V3) et significative dans les autres dérivations ( $\geq 1 \mathrm{~mm}$ en V1, V4-V5). Il n'y a pas de miroir visible. Ce sus-décalage convexe en haut, porte en France le nom d' « onde de Pardee » depuis sa description en 1920 [1] : «Elle commence d'un point élevé sur la défle-

P. Taboulet $(\bowtie)$

Hôpital Saint-Louis, Assistance publique-hôpitaux de Paris,

service des urgences, 1, avenue Claude Vellefaux,

F-75010, Paris, France

e-mail : pierre.taboulet@sls.aphp.fr xion de l'onde $\mathrm{R} »$. Elle englobe l'ascension du segment ST, précède ou accompagne le rabotage des ondes $\mathrm{R}$ puis régresse en quelques heures. La littérature anglaise préfère nommer ce sus-décalage très particulier tombstone wave (pierre tombale) en raison de sa forme et de son mauvais pronostic [2]. L'ensemble est compatible avec une occlusion récente de l'interventriculaire antérieure responsable d'un infarctus de mauvais pronostic (tachycardie, bloc bifasciculaire, QRS larges, onde de Pardee).

Conflit d'intérêt : les auteurs ne déclarent aucun conflit d'intérêt.

\section{Références}

1. Pardee HEB (1920) An electrocardiographic sign of coronary artery obstruction. Arch Int Med 26:244-57

2. Balci B, Yesildag O (2003) Correlation between clinical findings and "tombstoning" ECG. Am J Cardiol 92:1316-8 